\title{
Determination of Selected Heavy Metals Using Modified Glassy-Carbon Black Infused with Clay
}

\author{
Isaboke Peter Abel $^{1}$, Njagi Njomo² ${ }^{2}$ Obed Nyabaro ${ }^{3}$, Evans Kenanda Okemwa ${ }^{4}$ \\ ${ }^{1,3,4}$ Department of Chemistry, Kisii University \\ ${ }^{2}$ Department of Chemistry, University of Nairobi
}

\begin{abstract}
Atomic spectrometric methods are expensive and not suitable for in situ analysis due to the ponderous and complicated instruments. Contrary to electrochemical methods as an alternative to these spectroscopic techniques have been accepted as the efficient methods to detect heavy metal ions due to their excellent sensitivity, short analysis time, portability, and low cost. This study provided information on the novel instruments capable of real-time and in situ detection of heavy metal levels in studied soils and plants which were of importance in dealing with heavy metal pollution in the environment. It further provided an opportunity to the stakeholders to adopt to new methods of detecting heavy metals to reduce pollution in Kisii County.
\end{abstract}

Keywords: voltammetric, zeolite, hydroxyapatite, bismuth, electro-oxidation

\section{Introduction}

\subsection{Background of the Study}

Among all the electrochemical methods, linear sweep voltammetric analysis provides a powerful tool for the determination of metal ions, which possess high-sensitivity and can simultaneously analyze several heavy metal ions Basgelet al., 2005). The use of the chemically modified electrodes greatly improves the efficiency of accumulating target analytes without interferences compared with the conventional voltammetric techniques Basgel et al., 2005). The key point to obtain a good and reliable electrochemical sensor is the kind of materials that constitute the detection platform (Basgelet al., 2005). Different working electrodes are used in voltammetric determination of lead. These include mercury drop electrode, mercury film electrode, gold electrode, gold screen printed electrode, bismuth oxide screen printed electrode and renovated silver ring electrode (Abdel-Galeil et al., 2014). Carbon paste electrode is one of the most popular chemically modified electrodes used with voltammetric techniques. This electrode is prepared by mixing a graphite powder with a suitable binder and a material known as a modifier that improves the selectivity of the prepared electrode (Abdel-Galeil et al., 2014). Some modifiers that have been used with carbon paste electrode for the electrochemical determination of lead include zeolite, hydroxyapatite, and carbamoylphosphonic acid (AbdelGaleil et al., 2014).

\section{Literature Review}

\subsection{Clay modification and properties}

The use of clay minerals as electrode modifiers is the result of electrochemists desire to achieve a high quality electrode surface with the required properties, but also the result of their three decades effort to understand and control the processes that take place at electrode surface (Maghear 2013). The clay minerals that have been employed in this case belong to the class of phyllosilicates-layered hydrous aluminosilicates. An important characteristic of the clay mineral is the basal distance which depends on the number of intercalated water and exchangeable cations within the interlayer space (Maghear 2013). Other important properties of this structure regard the relatively large specific surface, ion-exchange properties, and ability to adsorb and intercalate organic compounds ( Maghear 2013).

Several techniques have been employed to cast the clay films, such as the low evaporation of colloidal suspensions on electrode surfaces, spin coating thin clay films, and claycarbon paste-modified electrodes Maghear (2013).

\section{Materials and Methods}

\subsection{Research Design}

Experimental research design was used in this study where the cases best contributing to the information needs of the study were selected. Anthropogenic regions in Kisii County were selected and this represented large scale farming which represented heavy human activities such as farming, spraying of chemicals and use of herbicides.

\subsection{Soil Digestion}

Prepared sample was oven dried at $105^{\circ} \mathrm{C}$ for 12 hours and $1 \mathrm{~g}$ of the sample was dissolved in $10 \mathrm{ml}$ of concentrated nitric acid and digestion tablet added. The mixture was heated until all the fumes ceased (to remove oxides of nitrogen). Hydrogen peroxide was added drop wise till a colorless solution was obtained and $10 \mathrm{ml}$ distilled water added and mixture was left to cool. The solution was filtered through filter paper whatman No. 42 into $100 \mathrm{ml}$ volumetric flask and topped with distilled water then put in clean labeled bottle for analysis using AAS (Buck Scientific 210 VGO Varian Co Ltd; Australia) with appropriate hollow cathode lamp at selected wavelength. (Begum et al, 2009).

\subsection{Preparation of stock solutions and standards.}

All stock solution were prepared by dissolving $0.5 \mathrm{~g}$ to $1 \mathrm{~g}$ of metal nitrate in $10 \mathrm{ml}$ of distilled water and then made up to $100 \mathrm{ml}$ of solution using distilled water. Through serial dilutions, standard working solutions of $\mathrm{Pb}, \mathrm{Mn}, \mathrm{Cd}$ and $\mathrm{Zn}$ were made which were used to generate calibration curves. 


\section{International Journal of Science and Research (IJSR) \\ ISSN (Online): 2319-7064}

Index Copernicus Value (2013): 6.14 | Impact Factor (2015): 6.391

3.4 Modification of the glassy carbon electrode with carbon black infused with clay

An electrochemical sensor was prepared by having $1 \mathrm{~g}$ of carbon black beads and $1 \mathrm{~g}$ of finely ground clay which were weighed and transferred into a $100 \mathrm{ml}$ a beaker. About $5 \mathrm{ml}$ of de-ionized water was added to the mixture in the beaker drop wise followed by stirring until homogenized uniform paste was obtained. The paste was then coated on the surface of the glass carbon electrode at a thickness of about $5 \mathrm{~mm}$ on its surface and was left to dry for 4 hours at room temperature. After it has dried, it was used as an electrochemical sensor for determination of the selected heavy metals. The modified glass carbon was washed thoroughly with de-ionized water and dried for 1 hour at a temperature of $40^{\circ} \mathrm{C}$ for new packing.

\section{Results and Discussion}

\subsection{Detection of heavy metals using modified glassy carbon electrode with clay}

Carbon black infused clay modified glass carbon platform electrode was prepared and used as an electrochemical sensor for the determination of heavy metals. The direct electro-oxidation and reduction behavior of heavy metals on the carbon black infused clay modified glassy carbon platform was carefully investigated by cyclic voltammetry. The results indicates that, heavy metals showed an increase of the oxidation peak current with shift of the oxidation peak potential in contrast to that on the bare glass carbon electrode as shown in figure 4.5.1 and figure 4.5.3 below. The carbon black infused clay modified glass carbon platform formed, has exhibited a remarkable electro-active activity towards oxidation of heavy metals. The electrochemical sensor exhibited some advantages, such as sensitivity; it could detect as low as $\times 10^{-6}$ values, good reproducibility; it can give the same values if the experiment is carried out by different intervals of time and long-term stability; it lasts for a very long period giving the same results accurately.

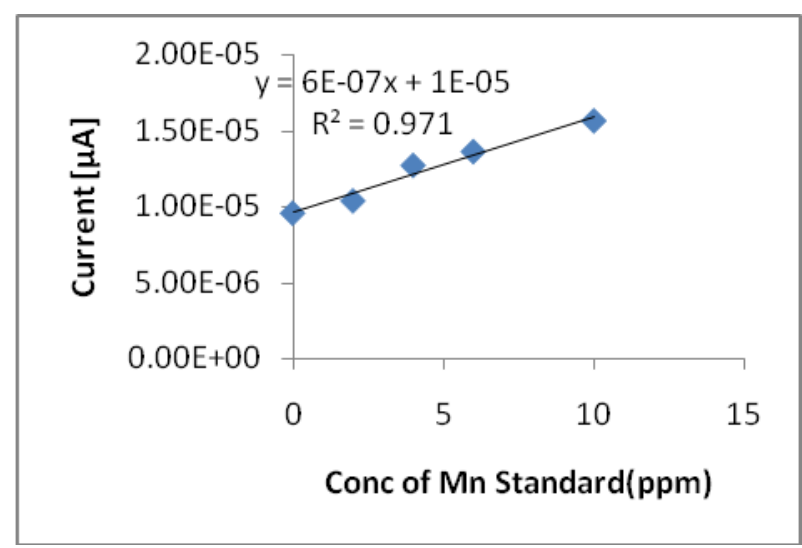

Figure 4.10.2: Calibration curve for Manganese for Voltammetric analysis at $1.00 \mathrm{~V}$

The detection of manganese standard concentration was done by reading the current peak in the voltammogram which was taken to the calibration curve to obtain the concentration of the metal as shown in the above figures.

The figure above shows the $\mathrm{CV}$ responses of $\mathrm{Mn}^{2+}$ at bare, bare coated with carbon black, and glassy carbon infused with clay electrodes. A relative small current response is observed at the bare electrode, which shows difficulty for the metal ions to be adsorbed onto the bare surface. On the other hand, for modified GCE electrode, the cyclic voltermmetry peak current values for the four metal ions are larger than those obtained from the bare and bare electrode coated with carbon black. This can be explained that the GCE modified with clay exerts negative charges on the surface. These charges can favor accumulation of increasing amount of positively charged metal ion on its surface. Hence, the clay can be as an excellent supporting material for heavy metal sensor. Thus the peak current of $\mathrm{Mn}^{2+}$ at the carbon black modified glassy carbon infused clay are greatly enhanced, which are attributed to glassy carbon infused with clay that exhibits a strong adsorption power of the heavy metal ions and hence an improved surface sensitivity of the electrode is observed.

\subsection{Results for Voltammetric analysis}

\section{Manganese(Mn)}

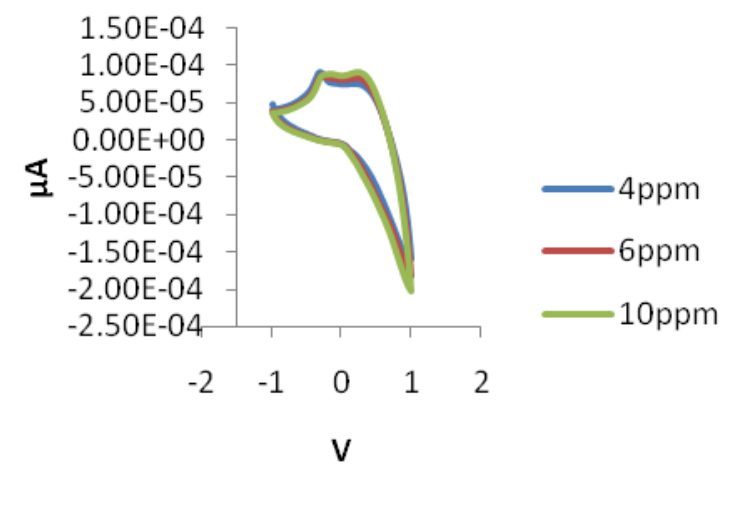

Figure 4.10.1: Standard Voltammogram for Manganese at $0.25 \mathrm{~V}$

\section{Sample S1}

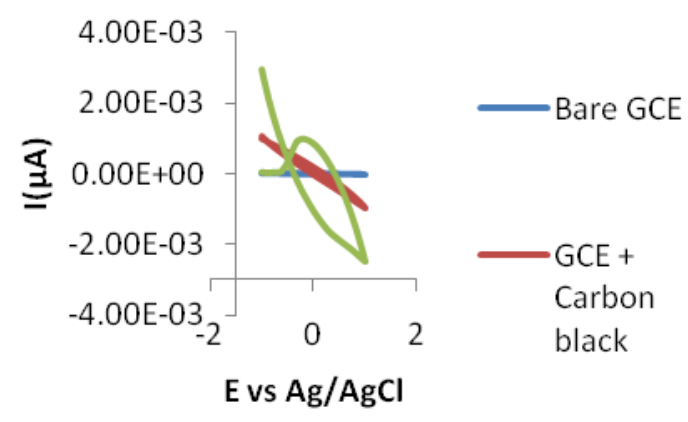

Figure 4.10.9: Voltammogram for Sample Soil 1

Determination of selected heavy metals from the above sample soil (1) was done by reading all the current peak voltammogram for relevant electrodes from the figure and taken to the standard voltammogram curves for specific 


\section{International Journal of Science and Research (IJSR) \\ ISSN (Online): 2319-7064}

Index Copernicus Value (2013): 6.14 | Impact Factor (2015): 6.391

metal to be determined and read the concentration which was the concentration of the metal in the soil.

\section{Conclusion}

The concentration of the heavy metals that were analysed $(\mathrm{Pb}, \mathrm{Zn}, \mathrm{Mn}$ and $\mathrm{Cd})$ are all far below the maximum tolerable levels set by WHO for agricultural soil. The results obtained showed that the soil is not polluted by various pollutants and not harmful for recreational and agricultural purposes. It is therefore suggested that the soil in Kisii County with its low levels of heavy metals should be utilized for agricultural farming. No remediation is needed because the concentration of heavy metals is below the tolerable amount as set by WHO. I recommend that the carbon black infused clay modified glassy carbon platform is the easiest electrochemical sensor which can be used for the analysis of heavy metals as compared with the Atomic Absorption Spectroscopy machine due to the fact that the materials used for its development is readily available and cheap.

\section{Recommendations}

The content of the heavy metals in water in Kisii County should be carried out to determine the concentration of the heavy metals in the water whether it conforms to the one found in the soil and to create awareness to the surroundings.

\section{References}

[1] Adela Maghear (2013). Development of new types of composite electrodes based on natural clays and their analytical applications.

[2] Abdel-Galeil M.M, Ghoneim, M.M, El-Desoky, S.H, Hattori, T and Matsuda A, (2014). Anodic Stripping Voltammetry Determinaton of Lead ions using Highly Sensitive Modified Electrodes Based on Multi-walled Carbon Nanotube. Journal of Chemistry and Biochemistry Dec 2014, Vol. 2.2001: 2-5

[3] Basgel, S. and Erdemoglu, S. B. (2006). Determination of Mineral and Trace Elements in Some medicinal Herbs and Their Infusions Consumed in Turkey. Journal of Environmental Science, 359: 82-89. 